\title{
Commentary PTEN deficiency: a role in mammary carcinogenesis
} Teresa Petrocelli* and Joyce M Slingerland ${ }^{\star \dagger}$

*Sunnybrook and Women's College Health Sciences Centre, Toronto, Ontario, Canada

tDepartment of Medical Biophysics, University of Toronto, Toronto, Ontario, Canada

Correspondence: Joyce M Slingerland, Sunnybrook and Women's College Health Sciences Centre, 2075 Bayview Avenue, Toronto, Ontario M4N 3M5, Canada. Tel: +1 416480 6100, ext 3494; fax: +1 416480 5703; e-mail: joyce.slingerland@utoronto.ca

Received: 5 June 2001

Breast Cancer Res 2001, 3:356-360

Revisions requested: 6 July 2001

Revisions received: 29 August 2001

Accepted: 10 September 2001

(C) 2001 BioMed Central Ltd

Published: 1 October 2001

(Print ISSN 1465-5411; Online ISSN 1465-542X)

\begin{abstract}
The PTEN gene is often mutated in primary human tumors and cell lines, but the low rate of somatic PTEN mutation in human breast cancer has led to debate over the role of this tumor suppressor in this disease. The involvement of PTEN in human mammary oncogenesis has been implicated from studies showing that germline PTEN mutation in Cowden disease predisposes to breast cancer, the frequent loss of heterozygosity at the PTEN locus, and reduced PTEN protein levels in sporadic breast cancers. To assay the potential contribution of PTEN loss in breast tumor promotion, Li et al. [1] crossed Pten heterozygous mice with mouse mammary tumor virus-Wnt-1 transgenic (Wnt-1 TG, Pten+/-) mice. Mammary ductal carcinoma developed earlier in Wnt-1 TG, Pten+l- mice than in mice bearing either genetic change alone, and showed frequent loss of the remaining wild-type PTEN allele. These data indicate a role for PTEN in breast tumorigenesis in an in vivo model.
\end{abstract}

Keywords: mammary carcinogenesis, PKB/Akt, PTEN, Wnt-1

\section{Introduction}

Cancer is a multi-step process involving the mutation of genes regulating cell proliferation, differentiation, and survival, leading to escape from normal tissue boundaries and sustained angiogenesis [2]. Given the plethora of genetic alterations observed in primary breast cancers, it has been difficult to establish which are involved in initiation, progression and metastasis. Despite often significant difficulties in the interpretation of their relevance to human disease, mouse models have provided experimental tools to investigate genetic pathways altered in breast cancer. Furthermore, the interbreeding of different TG or genedeficient mouse models can reveal the potential for cooperation between different signaling pathways.

\section{MMTV-Wnt-1 TG mice develop mammary tumors}

Mammary tumors induced following mouse mammary tumor virus (MMTV) infection have revealed oncogenes involved in murine mammary tumorigenesis. Random insertion of proviral MMTV DNA into mouse mammary epithelial cells results in insertional mutagenesis and oncogenic activation of various genes, including those of the Wnt, Fgf, and notch families, and elF-3p48. The first proto-oncogene to be cloned from MMTV-induced mammary cancers was Wnt-1 [3], a member of a family of secreted cysteine-rich glycoproteins, which controls cell fate/patterning through stabilization of $\beta$-catenin and activation of the downstream transcription factor $\mathrm{T}$ cell factor

GSK-3 $\beta=$ glycogen synthase kinase-3 $\beta$; ILK = integrin-linked kinase; LOH = loss of heterozygosity; MMTV = mouse mammary tumor virus; $\mathrm{mTOR}=$ mammalian target of rapamycin; PI3K = phosphatidylinositol $3^{\prime}$-kinase; PKB = protein kinase B; TCF/LEF $=\mathrm{T}$ cell transcription factor; $\mathrm{TG}=$ transgenic. 
(TCF/LEF). MMTV-Wnt-1 TG mice develop mammary tumors histopathologically similar to human breast cancers. These mice develop extensive mammary hyperplasia, and tumors progress to adenocarcinomas in a temporally predictable manner [4]. Although overexpression of Wnt-1 has not been observed in human breast cancers, several downstream components of the Wnt signaling pathway are deregulated in human cancers, including adenomatous polyposis coli, $\beta$-catenin, c-Myc, and cyclin $D_{1}$ [5]. Moreover, overexpression of a stable transcriptionally active $\beta$-catenin in a mouse mammary model induced multiple aggressive mammary adenocarcinomas [6]. By breeding MMTV-Wnt-1 TG mice with mice carrying alterations in genes implicated in breast cancer, potential synergies between pathways involved in breast oncogenesis can be defined. Li et al. employed this strategy, crossing mice heterozygous for PTEN with a MMTVWnt-1 TG model, to assay the relevance of PTEN deficiency to murine mammary tumorigenesis in an in vivo model [1].

\section{PTEN and cancer}

Early cytogenic analysis revealed frequent abnormalities within chromosome 10 involving the $10 \mathrm{q} 23$ region in many cancers (reviewed in [7]). The PTEN gene, located at chromosome $10 \mathrm{q} 23$, was identified as a candidate tumor suppressor gene frequently deleted at chromosome 10 q23 in primary cancers, including brain, prostate and breast cancer $[8,9]$. The tumor suppressor role for PTEN was further supported by the discovery that the autosomal dominant multineoplasia syndrome, Cowden disease, is associated with germ-line PTEN mutations [10]. Family members with Cowden disease, both male and female, have an increased incidence of breast cancer [11-13]. Moreover, somatic PTEN mutations are found frequently in endometrial carcinomas, malignant gliomas, and melanomas [14-16].

The PTEN gene product is a lipid phosphatase [8] that preferentially dephosphorylates phosphoinositides at the D3 position of the inositol ring [17]. It opposes the effects of phosphatidylinositol 3-kinase (PI3K) by dephosphorylating its lipid products. The products of PI3K activity are required for activation of protein kinase $B(P K B)$, also known as Akt, a serine/threonine kinase involved in cell growth and survival (review in [18]), whose constitutive activation has transforming potential [19]. PTEN may thus inhibit carcinogenesis through its inhibitory effect on PKB/Akt. One of the known substrates of PKB is glycogen synthase kinase-3 $\beta$ (GSK-3 $\beta$ ). GSK-3 $\beta$ is phosphorylated and inactivated by PKB/Akt [18].

Increasing data have implicated PTEN loss in breast carcinogenesis. While loss of heterozygosity $(\mathrm{LOH})$ of the PTEN locus is frequent in sporadic breast carcinoma [20], particularly in late stage disease [21], the very low rate of somatic intragenic PTEN mutations led some investigators to suggest that PTEN is not involved in breast tumor progression [22-26]. More recently, however, immunohistochemical analysis revealed frequent loss or reduction of PTEN protein in primary breast cancers [27]. Furthermore, while three different groups showed an embryonic lethal phenotype in PTEN knockout mice, Pten+/- mice develop breast cancers with relatively long latencies and different frequencies depending on the genetic strain used [28-30]. In one study, one-half of the Pten+/- mice developed breast tumors [31]. Despite the differing incidence of mammary cancers in the different genetic backgrounds of these PTEN-deficient strains, the evidence from the knockouts, coupled with the data of Li et al. [1], support a role for this tumor suppressor in mammary oncogenesis.

\section{Lessons from Wnt-1 TG, Pten+/- mice}

By crossing PTEN heterozygotes with MMTV-Wnt-1 TG mice, Li et al. [1] demonstrated a synergy between these two pathways and identified a role for PTEN in murine breast tumor promotion or progression. Infiltrating ductal cancers developed earlier in Wnt-1 TG, Pten+/- mice compared with Pten+/- mice or MMTV-Wnt-1 TG animals. The majority of tumors tested from Wnt-1 TG, Pten+/- animals showed loss of the remaining wild-type allele. Moreover, nontumorous mammary glands in Wnt-1 TG, Pten+/- mice showed frequent multifocal intraductal carcinoma both adjacent to and distant from the invasive tumors, while MMTV-Wnt-1 TG mice showed only ductal hyperplasia in grossly unaffected glands. In addition, the invasive cancers in Wnt-1 TG, Pten+/- mice had a less differentiated histopathology suggestive of a more aggressive phenotype.

PKB activation, as demonstrated by immunostaining of tumors for phospho-PKB, was seen only in a patchy distribution in tumors from Wnt-1 TG, Pten+/- mice. Moreover, PKB activation as assayed by this method was not observed in tumors from Wnt-1 TG animals. The authors reported reductions in PTEN protein by immunohistochemical analysis in tumors from Wnt-1 TG, Pten+l- mice whether or not they showed PTEN LOH. It is thus a little surprising that focal areas of PKB/Akt activation were seen only in tumors from Wnt-1 TG, Pten+/- animals showing PTEN LOH. The accuracy of assaying PKB activation by immunohistochemical analysis using antibody against the phosphorylated active form of PKB has not been definitively established.

The relevance of Wnt-1 TG, Pten+/- murine tumorigenesis to spontaneous breast cancer formation in humans is not entirely clear. It is possible that the enhanced tumor formation in the Wnt-1 TG, Pten+/- animals merely reflects synthetic synergy between two susceptible strains of mice. While there may be a synergy between the Wnt-1 and PTEN pathways in the Wnt-1 TG, Ptent/- tumors, 
there was no clear evidence for involvement of the PTEN/PKB pathway in MMTV-Wnt-1-mediated tumorigenesis. Li et al. found no increase in PKB activation in Wnt-1 TG tumors, and none of these tumors showed reduction to hemizygosity at the PTEN locus.

One intriguing possibility is that Wnt-1 overexpression and PTEN loss may interact by each contributing to inhibition of GSK-3 $\beta$ [32]. Following insulin or receptor tyrosine kinase stimulation, PKB phosphorylates and inhibits GSK-3 $\beta$. Wnt signaling causes a conformational inhibition of GSK-3 $\beta$ within a complex with axin, the adenomatous polyposis coli protein and $\beta$-catenin. Whereas in normal cells cross-talk between Wnt and receptor tyrosine kinase signaling does not usually occur, there is some evidence that the phosphorylation state of GSK-3 $\beta$ can influence Wnt signaling ([32] and references therein). GSK-3 $\beta$ inhibition would lead to increased cyclin $D_{1}$ stability [33], and stabilization of $\beta$-catenin with increased mitogenic transcriptional activity via the $\beta$ catenin-TCF/LEF complex [34]. PKB may not be an obligate target of PTEN loss since only 'patchy' activation of PKB was seen in Wnt-1 TG, Pten+/- mammary tumors, as assessed by immunohistochemical analysis. Recent reports suggest that the integrin-linked kinase (ILK) can mediate PI3K-dependent inactivation of GSK$3 \beta$ [35-37]. Although ILK can phosphorylate and activate PKB [38], it may also inhibit GSK-3 $\beta$ directly, independent of PKB in some cells. In oncogenesis, ILK-dependent GSK-3 $\beta$ inhibition could potentially contribute to Wnt-1 signaling and $\beta$-catenin-dependent transcriptional effects. In Wnt-1 TG, Pten+/- tumors, where PKB activation is 'patchy', activation of ILK via PTEN loss may lead directly to GSK-3 $\beta$ inactivation. PTEN loss may synergise with Wnt-1 through activation of ILK, with or without PKB activation, leading to GSK-3 $\beta$ inhibition. While this mechanistic model for cooperation between PTEN loss and Wnt1 activation may be provocative, evidence for cross-talk between these pathways in human mammary tumorigenesis has yet to be established.

Since PKB, a key PI3K effector downstream of PTEN, has been shown to inhibit apoptosis and promote cell cycle progression, the authors compared proliferation rates (by Ki67 staining) and assayed apoptosis in tumors from Wnt-1 TG, Ptent/- mice and in tumors from MMTVWnt-1 TG animals. Surprisingly, no differences in either were found. Activated PKB/Akt has been shown to enhance survival signals in breast epithelial cells [39]. Other methods to assay apoptosis would have strengthened the conclusions drawn by Li et al. Since the tumors in these two models both have very high proliferation rates, a subtle difference may have been missed by Ki67 staining. Flow cytometric analysis might have been useful, but the high content of stromal cells observed in the Wnt1 TG, Pten+/- tumors would have precluded accurate analysis without tumor microdissection. Since PTEN inhibits $S$ phase entry by increasing levels of the cdk inhibitor, p27, in certain cell types [40,41], and since activated PKB/Akt can stabilize cyclin D1 through its inhibitory action on GSK-3 $\beta$ [33], an increased rate of cellular proliferation might have been expected in Wnt-1 TG, Pten+/- tumors.

An additional possibility is that PTEN loss may influence tumorigenesis and the rapidity of tumor growth in vivo by increasing tumor cell invasiveness. It was recently shown that HER2/ErbB2 activation of PI3K-dependent signaling increases mammary epithelial cell invasive potential in vitro [42]. Moreover, PTEN dephosphorylates focal adhesion kinase and inhibits integrin-mediated cell spreading and cell migration [43]; thus, reduced PTEN expression could favor a metastatic phenotype. It is unfortunate that the small number of animals assayed for metastatic tumors precluded a definitive conclusion regarding the role of PTEN in metastasis in Li et al.'s study [1].

Given that increased PI3K and PKB/Akt signaling have also been shown to mediate angiogenesis through increased expression of vascular endothelial growth factor [44], loss of PTEN may promote tumor growth in vivo by an angiogenic mechanism. While reconstitution of PTEN expression in U87MG glioma cells failed to inhibit proliferation in culture, it caused a dramatic reduction in tumor growth in vivo in a murine orthotopic brain tumor model [45]. The PTEN-mediated inhibition of tumor growth seen in this brain tumor model may reflect a reduction in tumor angiogenesis. It would be interesting to compare the extent of angiogenesis in mammary cancers arising in MMTV-Wnt-1 mice, in Wnt-1 TG, Pten+/- mice, and in Pten+/- mice. These models may be useful to assay the potential role of PTEN in regulating breast cancer growth through an effect on tumor vasculature.

\section{Conclusion}

$\mathrm{Li}$ et al. provide compelling evidence for synergy between Wnt activation and loss of the PTEN tumor suppressor in promoting mammary carcinoma development and growth in vivo in mice. These data support further investigation of how downstream Wnt targets and PTEN inactivation may cooperate in mammary tumorigenesis. While the understanding of mechanisms of disease is in itself a laudable goal, an added utility of murine models lies in the preclinical testing of novel therapeutic agents. Since breast tumors form with predictable rapid kinetics in this model, Wnt-1 TG, Pten+/- mice may allow the testing of molecular-based therapies of potential utility in human tumors showing PTEN loss/mutation. One such candidate, the rapamycin analog $\mathrm{CC} 1779$, which inhibits the potential $\mathrm{PKB} / \mathrm{Akt}$ target mTOR, is under investigation by several groups [46]. Novel drugs that inhibit other cell cycle players may also prove to have therapeutic efficacy. 


\section{References}

1. Li Y, Podsypanina K, Liu X, Crane A, Tan LK, Parsons R, Varmus HE: Deficiency of Pten accelerates mammary oncogenesis in MMTV-Wnt-1 transgenic mice. BMC Mol Biol 2001, 2:2-10.

2. Hanahan D, Weinberg RA: The hallmarks of cancer. Cell 2000, 100:57-70.

3. Nusse R, Varmus HE: Many tumors induced by the mouse mammary tumor virus contain a provirus integrated in the same region of the host genome. Cell 1982, 31:99-109.

4. Tsukamoto AS, Grosschedl R, Guzman RC, Parslow T, Varmus $\mathrm{HE}$ : Expression of the int-1 gene in transgenic mice is associated with mammary gland hyperplasia and adenocarcinomas in male and female mice. Cell 1988, 55:619-625.

5. Morin PJ: Beta-catenin signaling and cancer. Bioessays 1999, 21:1021-1030.

6. Imbert A, Eelkema R, Jordan S, Feiner H, Cowin P: Delta N89 betacatenin induces precocious development, differentiation, and neoplasia in mammary gland. J Cell Biol 2001, 153:555-568.

7. Simpson L, Parsons R: PTEN: life as a tumor suppressor. Exp Cell Res 2001, 264:29-41.

8. Li J, Yen C, Liaw D, Podsypanina K, Bose S, Wang SI, Puc J, Miliaresis C, Rodgers L, McCombie R, Bigner SH, Giovanella BC, Ittmann M, Tycko B, Hibshoosh H, Wigler MH, Parsons R: PTEN, a putative protein tyrosine phosphatase gene mutated in human brain, breast, and prostate cancer. Science 1997, 275: 1943-1947.

9. Steck PA, Pershouse MA, Jasser SA, Yung WK, Lin H, Ligon AH, Langford LA, Baumgard ML, Hattier T, Davis T, Frye C, Hu R, Swedlund B, Teng DH, Tavtigian SV: Identification of a candidate tumour suppressor gene, MMAC1, at chromosome 10 q23.3 that is mutated in multiple advanced cancers. Nat Genet 1997, 15:356-362.

10. Liaw D, Marsh DJ, Li J, Dahia PL, Wang SI, Zheng Z, Bose S, Call KM, Tsou HC, Peacocke M, Eng C, Parsons R: Germline mutations of the PTEN gene in Cowden disease, an inherited breast and thyroid cancer syndrome. Nat Genet 1997, 16: 64-67.

11. Marsh DJ, Coulon V, Lunetta KL, Rocca-Serra P, Dahia PL, Zheng Z, Liaw D, Caron S, Duboue B, Lin AY, Richardson AL, Bonnetblanc JM, Bressieux JM, Cabarrot-Moreau A, Chompret A, Demange L, Eeles RA, Yahanda AM, Fearon ER, Fricker JP, Gorlin RJ, Hodgson SV, Huson S, Lacombe D, Eng C: Mutation spectrum and genotype-phenotype analyses in Cowden disease and Bannayan-Zonana syndrome, two hamartoma syndromes with germline PTEN mutation. Hum Mol Genet 1998, 7:507-515.

12. Schrager CA, Schneider D, Gruener AC, Tsou HC, Peacocke M: Clinical and pathological features of breast disease in Cowden's syndrome: an underrecognized syndrome with an increased risk of breast cancer. Hum Pathol 1998, 29:47-53.

13. Fackenthal JD, Marsh DJ, Richardson AL, Cummings SA, Eng C, Robinson BG, Olopade OI: Male breast cancer in Cowden syndrome patients with germline PTEN mutations. J Med Genet 2001, 38:159-164.

14. Kong D, Suzuki A, Zou TT, Sakurada A, Kemp LW, Wakatsuki S, Yokoyama T, Yamakawa H, Furukawa T, Sato M, Ohuchi N, Sato S, Yin J, Wang S, Abraham JM, Souza RF, Smolinski KN, Meltzer SJ, Horii A: PTEN1 is frequently mutated in primary endometrial carcinomas. Nat Genet 1997, 17:143-144.

15. Wang SI, Puc J, Li J, Bruce JN, Cairns P, Sidransky D, Parsons R: Somatic mutations of PTEN in glioblastoma multiforme. Cancer Res 1997, 57:4183-4186.

16. Tsao $H$, Zhang $X$, Benoit $E$, Haluska $F G$ : Identification of PTEN/MMAC1 alterations in uncultured melanomas and melanoma cell lines. Oncogene 1998, 16:3397-3402.

17. Maehama T, Dixon JE: The tumor suppressor, PTEN/MMAC1, dephosphorylates the lipid second messenger, phosphatidylinositol 3,4,5-trisphosphate. J Biol Chem 1998, 273:1337513378.

18. Downward J: Mechanisms and consequences of activation of protein kinase B/Akt. Curr Opin Cell Biol 1998, 10:262-267.

19. Mirza AM, Kohn AD, Roth RA, McMahon M: Oncogenic transformation of cells by a conditionally active form of the protein kinase Akt/PKB. Cell Growth Differ 2000, 11:279-292.

20. Singh B, Ittmann MM, Krolewski JJ: Sporadic breast cancers exhibit loss of heterozygosity on chromosome segment 10q23 close to the Cowden disease locus. Genes Chromosomes Cancer 1998, 21:166-171.
21. Bose S, Wang SI, Terry MB, Hibshoosh H, Parsons R: Allelic loss of chromosome $10 \mathrm{q} 23$ is associated with tumor progression in breast carcinomas. Oncogene 1998, 17:123-127.

22. Chen ST, Yu SY, Tsai M, Yeh KT, Wang JC, Kao MC, Shih MC, Chang JG: Mutation analysis of the putative tumor suppression gene PTEN/MMAC1 in sporadic breast cancer. Breast Cancer Res Treat 1999, 55:85-89.

23. Freihoff D, Kempe A, Beste B, Wappenschmidt B, Kreyer E, Hayashi Y, Meindl A, Krebs D, Wiestler OD, von Deimling A, Schmutzler RK: Exclusion of a major role for the PTEN tumoursuppressor gene in breast carcinomas. $\mathrm{Br} J$ Cancer 1999, 79: 754-758.

24. Feilotter HE, Coulon V, McVeigh JL, Boag AH, Dorion-Bonnet F, Duboue B, Latham WC, Eng C, Mulligan LM, Longy M: Analysis of the 10q23 chromosomal region and the PTEN gene in human sporadic breast carcinoma. Br J Cancer 1999, 79:718723.

25. Ueda K, Nishijima M, Inui H, Watatani M, Yayoi E, Okamura J, Yasutomi M, Nakamura Y, Miyoshi Y: Infrequent mutations in the PTEN/MMAC1 gene among primary breast cancers. Jpn J Cancer Res 1998, 89:17-21.

26. Rhei E, Kang L, Bogomolniy F, Federici MG, Borgen PI, Boyd J: Mutation analysis of the putative tumor suppressor gene PTEN/MMAC1 in primary breast carcinomas. Cancer Res 1997, 57:3657-3659.

27. Perren A, Weng LP, Boag AH, Ziebold U, Thakore K, Dahia PL, Komminoth P, Lees JA, Mulligan LM, Mutter GL, Eng C: Immunohistochemical evidence of loss of PTEN expression in primary ductal adenocarcinomas of the breast. $A m$ J Pathol 1999, 155: 1253-1260.

28. Di Cristofano A, Pesce B, Cordon-Cardo C, Pandolfi PP: Pten is essential for embryonic development and tumour suppression. Nat Genet 1998, 19:348-355.

29. Suzuki A, de la Pompa JL, Stambolic V, Elia AJ, Sasaki T, del Barco Barrantes I, Ho A, Wakeham A, Itie A, Khoo W, Fukumoto M, Mak TW: High cancer susceptibility and embryonic lethality associated with mutation of the PTEN tumor suppressor gene in mice. Curr Biol 1998, 8:1169-1178.

30. Podsypanina K, Ellenson LH, Nemes A, Gu J, Tamura M, Yamada KM, Cordon-Cardo C, Catoretti G, Fisher PE, Parsons R: Mutation of Pten/Mmac1 in mice causes neoplasia in multiple organ systems. Proc Natl Acad Sci USA 1999, 96:1563-1568.

31. Stambolic V, Tsao MS, Macpherson D, Suzuki A, Chapman WB, Mak TW: High incidence of breast and endometrial neoplasia resembling human Cowden syndrome in pten $+/-$ mice. Cancer Res 2000, 60:3605-3611.

32. Harwood AJ: Regulation of GSK-3: a cellular multiprocessor. Cell 2001, 105:821-824.

33. Diehl JA, Cheng M, Roussel MF, Sherr CJ: Glycogen synthase kinase-3beta regulates cyclin D1 proteolysis and subcellular localization. Genes Dev 1998, 12:3499-3511.

34. Rimerman RA, Gellert-Randleman A, Diehl JA: Wnt1 and MEK1 cooperate to promote cyclin D1 accumulation and cellular transformation. J Biol Chem 2000, 275:14736-14742.

35. Persad S, Attwell S, Gray V, Delcommenne M, Troussard A, Sanghera J, Dedhar S: Inhibition of integrin-linked kinase (ILK) suppresses activation of protein kinase B/Akt and induces cell cycle arrest and apoptosis of PTEN-mutant prostate cancer cells. Proc Natl Acad Sci USA 2000, 97:3207-3212.

36. Persad S, Troussard AA, McPhee TR, Mulholland DJ, Dedhar S: Tumor suppressor PTEN inhibits nuclear accumulation of beta-catenin and $\mathrm{T}$ cell/lymphoid enhancer factor 1-mediated transcriptional activation. J Cell Bio/ 2001, 153:1161-1174.

37. Delcommenne M, Tan C, Gray V, Rue L, Woodgett J, Dedhar S: Phosphoinositide-3-OH kinase-dependent regulation of glycogen synthase kinase 3 and protein kinase B/AKT by the integrin-linked kinase. Proc Natl Acad Sci USA 1998, 95: 11211-11216.

38. Persad S, Attwell S, Gray V, Mawji N, Deng JT, Leung D, Yan J, Sanghera J, Walsh MP, Dedhar S: Regulation of protein kinase B/Akt-serine 473 phosphorylation by integrin-linked kinase: critical roles for kinase activity and amino acids arginine 211 and serine 343. J Biol Chem 2001, 276:27462-27469.

39. Hutchinson J, Jin J, Cardiff RD, Woodgett JR, Muller WJ: Activation of Akt (protein kinase B) in mammary epithelium provides a critical cell survival signal required for tumor progression. Mol Cell Biol 2001, 21:2203-2212. 
40. Li DM, Sun H: PTEN/MMAC1/TEP1 suppresses the tumorigenicity and induces $\mathrm{G} 1$ cell cycle arrest in human glioblastoma cells. Proc Natl Acad Sci USA 1998, 95:15406-15411.

41. Cheney IW, Neuteboom ST, Vaillancourt MT, Ramachandra M, Bookstein R: Adenovirus-mediated gene transfer of MMAC1/PTEN to glioblastoma cells inhibits $S$ phase entry by the recruitment of p27Kip1 into cyclin E/CDK2 complexes. Cancer Res 1999, 59:2318-2323.

42. Ignatoski KM, Maehama T, Markwart SM, Dixon JE, Livant DL, Ethier SP: ERBB-2 overexpression confers PI $3^{\prime}$ kinasedependent invasion capacity on human mammary epithelial cells. Br J Cancer 2000, 82:666-674.

43. Tamura M, Gu J, Matsumoto K, Aota S, Parsons R, Yamada KM: Inhibition of cell migration, spreading, and focal adhesions by tumor suppressor PTEN. Science 1998, 280:1614-1617.

44. Jiang BH, Zheng JZ, Aoki M, Vogt PK: Phosphatidylinositol 3kinase signaling mediates angiogenesis and expression of vascular endothelial growth factor in endothelial cells. Proc Natl Acad Sci USA 2000, 97:1749-1753.

45. Wen S, Stolarov J, Myers MP, Su JD, Wigler MH, Tonks NK, Durden DL: PTEN controls tumor-induced angiogenesis. Proc Natl Acad Sci USA 2001, 98:4622-4627.

46. Hidalgo M, Rowinsky EK: The rapamycin-sensitive signal transduction pathway as a target for cancer therapy. Oncogene 2000, 19:6680-6686. 